\title{
Mindfulness and Group Cognitive Behavioural Therapy to Address Problematic Perfectionism
}

\author{
By Ester Senderey*
}

This paper presents the rationale and therapeutic components of a pilot group program which combined mindfulness skills and cognitive behavioural therapy to address problematic perfectionism (PP). PP is defined as the pursuit of extremely high standards despite negative outcomes and consequences in personal, academic and social areas of functioning. This pilot group used a psycho-educational approach, training participants in mindfulness skills and cognitive behavioural techniques to reduce procrastination, ruminative processes and general distress. Mindfulness is an ancient meditative practice that encourages acceptance and non-reactivity to different types of stimuli. Mindfulness in psychology has been used as a cognitive and behavioural tool to reduce anxiety and worry as well as to promote well-being. The paper discusses preliminary findings, initial participants' impressions and acceptability of the program followed by an identification of limitations of pilot program. Finally the paper offers recommendations for future research.

Keywords: Group therapy, Mindfulness, Problematic perfectionism.

\section{Introduction}

This paper focuses on a pilot group program addressing problematic perfectionism (PP). Perfectionism has been conceptualized as a personality disposition that may lead, with co-existing repetitive thinking, and anxiety related avoidant behaviour, to adverse outcomes. The group program has been designed to disrupt a cycle of distress and to reduce reinforcement factors. The skills training group targets the most common cognitive, emotional and behavioural maintaining factors resulting in negative outcomes. Following the presentation of the group framework, principles, structure and goals, the paper will delineate some of the limitations of the pilot program and will discuss responses from the participants of this initial group. Some recommendations for future research will be indicated last.

\section{Problematic Perfectionism and Trans-Diagnostic Processes}

\section{A Continuum Model}

Perfectionism is implicated in the onset and maintenance of many psychological disorders such as mood, eating and anxiety disorders.

\footnotetext{
${ }^{*}$ Psychology Clinic Manager, Australian College of Applied Psychology, Australia.
} 
Perfectionism is regarded as a trans-diagnostic, contributing and maintaining factor of the most common clinical disorders (Antony and Swinson 2009, Arping et al. 2008, Dudley et al. 2011, Egan et al. 2011, Flett and Hewitt 2002, Flett et al. 2007, Harvey et al. 2009). Perfectionism is considered a personality trait that can lead to not only excellence in achievement and performance, but to negative outcomes as well. PP is defined as pursuing self- imposed, extreme and demanding standards, despite negative outcomes such as anxiety, depression, troubled relationships and damaged self-esteem (Brustein 2014, Shafran et al. 2010).

Perfectionism can be conceptualized as a personality tendency in a continuum ranging from non-perfectionism, healthy perfectionism, and in the extreme, PP. In PP, self-worth is based exclusively on performance and achievement. Not surprisingly, harsh self-criticism, self-destructive behaviours, and painful emotions co-exist with PP (Shafran and Mansell 2001, Shafran et al. 2002, Shafran et al. 2010, Wade 2015). PP has also been termed "clinical perfectionism". In the current context, the term problematic was chosen to focus on the negative consequences of perfectionism and in an effort to minimise those negative consequences, rather than on perfectionistic strivings (high ambitions, standards of excellence). The focus of attention of the group program is the negative or problematic aspects of perfectionism while the adaptive aspects of perfectionism are acknowledged and encouraged. This approach is consistent with the model proposed by Kutlesa and Arthur (2008) which also viewed perfectionism in a continuum. Their group intervention attempted to embrace perfectionist strengths and strivings while minimising the debilitating consequences of perfectionism in areas such as personal identity, performance and health.

\section{Exposure Therapy Elements}

Clinical levels of anxiety are commonly found in people with PP (Egan et al. 2014). Exposure therapy is the treatment of choice for anxiety disorders. Exposure is a well-validated, effective psychological treatment for most anxiety disorders (Barlow 2008, Gallagher et al. 2014, Richard et al. 2011). It is understood as the confrontation of aversive experiences or feared stimulus (internal or external) which produces an undesirable reaction (anxiety, fear, distress), as a way to gradually decrease the strength of the current association between stimulus and response. Exposure as a strategy involves approaching a feared situation, intrusive thoughts or memories with the aim of obtaining corrective learning, which is the acquisition of a new behavioural repertoire. Exposure is the opposite of avoidant behaviour which inhibits new learning.

Carey (2011) maintains exposure is a trans-diagnostic treatment principle that is a core in all effective psychological interventions. He argues exposure is based on awareness and reorganization, vital steps in the process of achieving beneficial change. The Unified Protocol for Emotional Disorders outlined in Allen et al. (2008) is another relevant illustration of the use of exposure therapy elements in addressing common features across disorders. More details about 
the use of exposure therapy elements in this pilot program will be provided below in this paper.

Harvey et al. (2009) argued that there are common attentional, cognitive and behavioural processes underlying psychological disorders. They include selective attention, rumination, avoidance behaviour, safety behaviour and experiential avoidance (Higginson et al. 2011). Because repetitive thinking (rumination) and excessive worry are common companions of PP, and function to maintain distress (Blankstein and Lumley 2008, Wade 2015), they will be discussed next.

\section{Rumination and Worry}

Nolen-Hoeksema et al. (2008) defined rumination as "repetitive thinking about the causes, consequences and symptoms of one's negative affect" (p.569). Rumination has been associated with psychological distress because ruminators avoid processing experiences and negative emotions. As such, rumination acts as an avoidant emotional regulation strategy which obstructs effective problem solving (Bassanini et al 2010, Nolen-Hoeksema 1991, Short and Mazmanian 2013, Smith and Alloy 2009, Watkins 2009). Rumination maintains distress because the focus is on what went wrong instead of what can be done to make things better. Rumination interferes with effective problem solving. Blankstein and Lumley (2008) refer to rumination as a "brooding trap", a vicious cycle which exacerbates distress.

Rumination involves dwelling in repetitive and stereotypically rigid thinking generally about past events while worry (another self-focussed strategy) involves a preoccupation with potential future catastrophic events. Worry takes attention away from threatening thoughts and inhibits the autonomic anxiety response. Like rumination, worry inhibits emotional processing and effective problem-solving. Worry is a problem solving effort; however, because the problem is not current but hypothetical or outside the control or influence of the worrier, worry becomes useless and counterproductive. Worry is a verbal linguistic attempt to prevent future feared events. It involves "What if" questions and common themes include relationships, poverty, injury and incapacity, unemployment and social disgrace (Harvey et al. 2009). A rationale for training in mindfulness skills as a way to exit negative thinking and decrease rumination and worry is provided next.

\section{Mindfulness Training}

Mindfulness training is essential in obtaining metacognitive awareness (defined as thinking about thinking, awareness of own thought processes) and in accelerating experiential acceptance (Cayoun 2011, 2014, 2015). Mindfulness skills include the practice of behaviours, such as paying attention to, observing, describing the experience and fully immersing the self into the present moment (Linehan 1993, 2015). Mindfulness skills promote awareness 
and an exit to the ruminative mind, which perpetuates distress (Egan et al. 2014).

It is generally accepted that meditative practices like mindfulness enhance well-being (Kabat-Zinn et al. 1998). In the group context, mindfulness is deprived of any religious or spiritual connotations. Mindfulness skills can then be taught and practised in a group setting (Linehan 1993, 2015).

Mindfulness is defined as present awareness of experience as it unfolds, incorporating thoughts, feelings, actions, and bodily sensations. Moreover, attitudes related to mindfulness include gratitude, acceptance, non-judgmental mind and psychological flexibility.

Present moment awareness is contrasted to automaticity, auto-pilot mode, typical patterns of disconnection to the present when the mind is preoccupied with thoughts about the future, or entangled with past memories. This mode of being is referred as "autopilot" (Alidina 2010, Kabat- Zinn 2003, Nhat Hanh 1987 ) or the "wandering mind". The mind in "autopilot" is not per se an indication of pathology; but the most common state of the mind (default mode), as Killingworth and Gilbert noted (as cited in Niemiec 2014):

"The human mind is a wandering mind, and a wandering mind is an unhappy mind. The ability to think about what is not happening is a cognitive achievement that comes at an emotional cost" (p.10).

Baer (2003) reviewed the existing literature (experiential studies) about mindfulness as a psychological tool. She concluded that studies revealed mindfulness is an effective psychological intervention, which promotes relaxation, cognitive, emotional and behavioural changes. The practice of mindfulness may act as a type of exposure strategy because the regular practice of mindfulness skills facilitate confrontation of internal experiences (thoughts and feelings) with a non-judgmental attitude leading to a reduction in anxiety, stress and depression (Ball et al. 2007, Brustein 2014, Carmody et al. 2009, Teasdale et al. 1995).

From a mindfulness perspective, what is emphasized is non-doing, notstriving, and to fully attend to current experience, regardless of whether the experience is pleasant, unpleasant or neutral (Kabat-Zinn 1990). As opposed to a relaxation practice, which aims to trigger a "relaxation response", meditative practices like mindfulness are not goal oriented.

\section{Self-acceptance}

People with PP have a fragile self-esteem. A feeble self-esteem is the result of a global negative opinion of the self which is constantly reinforced by the difficulty in attaining the desired level of aspiration, competency and achievement. Self-esteem is a complex system affecting the way a person feels about themselves, the way they interact with others and their overall sense of satisfaction in life and well-being. It has cognitive (self-description), affective (self-esteem) and evaluative aspects (self-evaluation) (Guindon 2010). 
In PP, self-esteem is contingent upon unrealistic achievement and performance standards. The "paradox of self-acceptance" can then offer an alternative approach to building self-esteem. A paradox is a self-contradictory statement based on Eastern philosophy, where the basis of change is accepting and embracing limitations to be able to overcome them. Self- acceptance is viewed as protective of self-esteem and independent of achievements (Burns 1983).

\section{Procrastination and Avoidant Behaviour}

Perfectionism and procrastination are intimately related (Basco 2010). Procrastination is a behaviour pattern of deliberate action postponement: "making a decision for no valid reason to delay or not complete a task or goal you have committed to, and instead doing something of lesser importance, despite there being negative consequences to not following through on the original plan or goal" (Saulsman and Nathan 2008: 2). Flett, Hewitt, Davis and Sherry coined the term "the perfectionistic procrastinator". The perfectionistic procrastinator is described as a person who has frequent negative automatic thoughts in connection to achieving perfection as a way to gain approval. Additionally, he/she typically suffers from a negative self-concept, decreased sense of self-efficacy, extreme fear of failure and high dysphoria (Flett et al. 2004). The authors recommend psychological interventions directed at those specific areas with the aim of decreasing self-criticism and rumination, promoting effective problem solving and realistic goal setting, as well as ameliorating distress (anxiety, depression and stress).

\section{Nobody Is Perfect (Nip): Group Therapy Addressing Problematic Perfectionism}

Keeping in mind the common psychological processes and difficulties described in the previous section, NIP used well validated cognitive, behavioural and mindfulness skills as main strategies to reduce distress and promote well-being (Egan et al. 2014, Senderey 2014a, 2014b).

NIP used mindfulness as an intervention strategy why shares some similarities to exposure therapy, as NIP participants learn skills to confront aversive internal (thoughts, feelings, emotional states) and external (interpersonal situation, conflict, disagreement) stimuli, to obtain increased psychological flexibility and a non-judgemental attitude (new behavioural or attitudinal repertoire). Participants learn to face thoughts and emotions without using cognitive, emotional or behavioural avoidance. Avoidance or suppression reinforces old maladaptive patterns. NIP participants are encouraged to face anxiety provoking thoughts and emotions to achieve habituation and reduce the use of cognitive, emotional or behavioural avoidance strategies. As noted previously, the practice of mindfulness then serves as a type of exposure strategy. The author of this article is not claiming mindfulness is equivalent of 
exposure therapy. Mindfulness skills were used in NIP as a way to assist participants in facing painful thoughts and emotions, with a non-judgmental stance (Ball et al. 2007, Brustein 2014, Carmody et al. 2009).

\section{Group Approach using Adult Learning Principles}

A group based on adult learning principles (Imel 1998, McNeill et al. 2006) was designed and implemented in a university based psychology clinic, at the Australian College of Applied Psychology (ACAP). ACAP offers postgraduate training in clinical and professional psychology.

The group program was designed on the following foundations:

1. Capacity-building (skill training)

2. Participant-centred learning

3. Collaboration between participants and facilitators

4. Relevance of group materials recognizing that adults learners have multiple and competing responsibilities (academic, work, family, health)

5. Establishment of a supportive and respectful group environment

6. A psycho-education and preventive approach.

The main focal points of the group were sharing information, resources and tools to facilitate change of unproductive behaviour, tackle negative consequences of perfectionism, problem solve and decrease distress. To that purpose, a range of evidence based strategies were discussed and practiced. Strategies include mindfulness, acceptance, behavioural functional analysis, distress tolerance, problem solving, behavioural activation and emotional regulation skills.

The clinic manager (1) and 2 postgraduate students conducted the initial pilot program. The program was advertised internally to recruit participants who wanted to address problematic perfectionism. A small number of participants joined the first group $(n=6)$. Two participants did not complete the program, leaving four participants who completed the first pilot program. Participants were interviewed and completed questionnaires before and after the program. The limited number of participants prevents a quantitative evaluation of results; however, anecdotal information and feedback received from participants during a group evaluation session were extremely promising. In order to evaluate the effectiveness of the program to decrease distress and to foster well-being, two more pilot programs are planned. Additionally, a research study in progress is investigating perfectionism, procrastination, and well-being factors in relation to retention rates in a sample of Psychology students. The model used in this pilot program was consistent with the idea of building resilience and empowering participants to take responsibility to make changes in their lives. To that effect, information about a cognitive-behavioural model of PP (Shafran et al. 2010, Steele et al. 2012) allowed participants to 
understand the way in which PP contributes to achieve undesirable effects. The group was based on experiential learning, collaboration and level of readiness to tackle PP.

In the group, participants were trained to refocus their attention from the "wondering mind" to their present moment by practising mindfulness skills. A 15 minute meditation called open hearted -acceptance meditation (McGonical 2014) was practiced at the beginning of each session. The same script was repeated every session to promote habituation. Additionally, participants were trained to use observation, description and participation in activities in a nonevaluative manner (Bein 2013, Linehan 1993, 2015).

Group participants were taught the "What" and "How" of mindfulness micro-skills (Linehan 2015). Additionally, DBT concepts of acceptance (self, others and experiential) and distress tolerance were discussed and practised in session and then given as homework tasks.

1. The writer of this article has been formally trained in Dialectical Behaviour Therapy by Dr. Jennifer Sayrs and Dr. Adam Payne (2004) as well as Mindfulness based Stress Reduction, in a 7day professional program by Dr. Jon Kabat Zinn and Dr. Saki Santorelli (2006). Additionally, she participated in a professional retreat conducted by Dr. J. Carmody in New Zealand (2005).

2. The postgraduate students were Master of Psychology (Clinical) candidates.

\section{Objectives}

NIP is an eight-week group program addressing some of the negative consequences of perfectionism. The group format was regarded as an optimum learning milieu for adults experiencing PP. Additionally, a group format is an efficient and practical way to deliver evidence-based interventions to a group of people with emotional disorders (Bullis et al. 2015, Scott 2011).

The objectives, outcomes and skills covered in group training are listed in the table below. 
Table 1. NIP Group Training

\begin{tabular}{|c|c|c|}
\hline Objectives & Outcome & Skill Training \\
\hline $\begin{array}{l}\text { To promote wellbeing } \\
\text { by increasing } \\
\text { psychological flexibility }\end{array}$ & $\begin{array}{l}\text { Reduced rumination and } \\
\text { worry; } \\
\begin{array}{l}\text { Decreased emotional, } \\
\text { cognitive and behavioral } \\
\text { reactivity; }\end{array} \\
\text { Improved mood. }\end{array}$ & 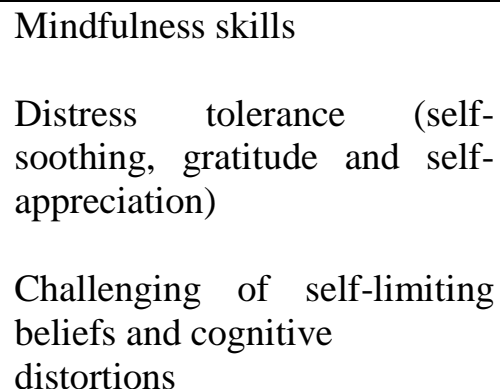 \\
\hline $\begin{array}{l}\text { To enhance skillful } \\
\text { behaviour }\end{array}$ & $\begin{array}{l}\text { Reduced avoidance; } \\
\text { Reduced procrastination } \\
\text { and other avoidance } \\
\text { behaviour; } \\
\text { Effective problem solving. }\end{array}$ & 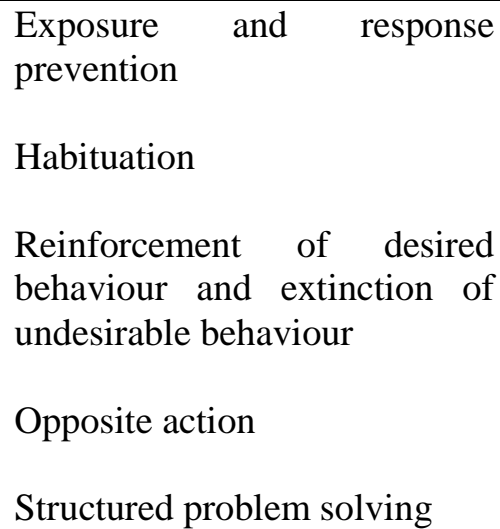 \\
\hline $\begin{array}{l}\text { To improve } \\
\text { self-esteem }\end{array}$ & $\begin{array}{l}\text { Decreased self-criticism, } \\
\text { Unconditional } \\
\text { selfacceptance and } \\
\text { validation }\end{array}$ & $\begin{array}{l}\text { Self-esteem independence of } \\
\text { achievement } \\
\text { Widening sources of self- } \\
\text { esteem } \\
\text { Self-acceptance }\end{array}$ \\
\hline $\begin{array}{l}\text { To improve } \\
\text { emotional regulation }\end{array}$ & $\begin{array}{l}\text { Mindfulness of emotions } \\
\text { Emotional non-reactivity }\end{array}$ & $\begin{array}{l}\text { Mindfulness skills } \\
\text { Acceptance }\end{array}$ \\
\hline
\end{tabular}

\section{Psychological Interventions}

Psychological interventions were aiming to disrupt cognitive and behavioural processes maintaining distress (Harvey et al. 2011). Skill training incorporated strategies borrowed from behaviour therapy, dialectical behaviour therapy (Linehan 1993, 2015, Robins et al. 2004), motivational interviewing, mindfulness based stress reduction (Kabat-Zinn 1990) and mindfulnessintegrated cognitive behavioural therapy (Cayoun 2014). Key cognitive maintaining factors amenable to change were targeted, in particular ruminative processes (Flett and Hewitt 2008).

Table 2 provides a list of psychological strategies and approaches used in the group program. 
Table 2. Weekly Goals and Psychological Interventions

\begin{tabular}{|c|c|c|}
\hline Week & Goals & Psychological Interventions \\
\hline 1 & $\begin{array}{l}\text { Understanding and awareness of the } \\
\text { negative consequences of problematic } \\
\text { perfectionism. }\end{array}$ & Psycho-education \\
\hline 2 & $\begin{array}{l}\text { Information about readiness for change. To } \\
\text { increase motivation to implement a plan of } \\
\text { change. }\end{array}$ & Motivational Interviewing \\
\hline 3 & $\begin{array}{l}\text { Awareness of patterns, triggers and } \\
\text { maintaining factors }\end{array}$ & $\begin{array}{l}\text { Psycho-education } \\
\text { Cognitive Behaviour Therapy }\end{array}$ \\
\hline 4 & $\begin{array}{l}\text { Non-reactivity } \\
\text { Emotional regulation } \\
\text { Self-soothing }\end{array}$ & $\begin{array}{l}\text { Mindfulness Integrated } \\
\text { Cognitive Behaviour Therapy } \\
\text { Cognitive \& Dialectical } \\
\text { Behaviour Therapy } \\
\text { Mindfulness Based Stress } \\
\text { Reduction }\end{array}$ \\
\hline 5 & $\begin{array}{l}\text { Behavioural change } \\
\text { Distress tolerance }\end{array}$ & $\begin{array}{l}\text { Mindfulness Integrated } \\
\text { Cognitive Behaviour Therapy } \\
\text { Cognitive \& Dialectical } \\
\text { Behaviour Therapy } \\
\text { Mindfulness Based Stress } \\
\text { Reduction }\end{array}$ \\
\hline 6 & Self-esteem enhancement & $\begin{array}{l}\text { Mindfulness Based Stress } \\
\text { Reduction }\end{array}$ \\
\hline 7 & Acceptance and validation & $\begin{array}{l}\text { Mindfulness Integrated } \\
\text { Cognitive Behaviour Therapy } \\
\text { Cognitive \& Dialectical } \\
\text { Behaviour Therapy } \\
\text { Mindfulness Based Stress } \\
\text { Reduction }\end{array}$ \\
\hline 8 & Relapse prevention & Relapse prevention \\
\hline
\end{tabular}

A person's readiness to change in this context was discussed with group participants. Prochaska's (1994) trans-theoretical stages of change model was used to assist participants to understand and to identify the phase they found themselves in, at the time of starting the group (Dalton \& Gotlieb, 2003).Tasks of each phase were discussed and ideas or strategies to facilitate change were explored (Rollnick et al. 1999).

Group participants were provided with a list of the program contents and learning goals. A weekly thematic list is presented in Table 3 below. 
Table 3: Weekly Group Topics and Learning Goals

\begin{tabular}{|c|c|c|}
\hline Week & Topic & Learning Goals \\
\hline 1 & $\begin{array}{l}\text { Understanding } \\
\text { problematic } \\
\text { perfectionism (PP) }\end{array}$ & $\begin{array}{l}\text { What is perfectionism? Different types, origin and } \\
\text { manifestations. Impact on your life. Healthy or healthy? } \\
\text { Striving for excellence and PP }\end{array}$ \\
\hline 2 & $\begin{array}{l}\text { Examining how } \\
\text { ready you are to } \\
\text { change PP }\end{array}$ & $\begin{array}{l}\text { Factors that facilitate or impede change. The change } \\
\text { cycle. Current position in the cycle. Tasks of each } \\
\text { phase. Decisional balance: cost and benefits of change }\end{array}$ \\
\hline 3 & The PP cycle & $\begin{array}{l}\text { Your vulnerability, triggers, protective and maintaining } \\
\text { factors. How the cycle goes \& how to exit. Current and } \\
\text { alternative cycle. Behavioural change goal } \\
\text { identification worksheet. Goal setting }\end{array}$ \\
\hline 4 & $\begin{array}{l}\text { Thinking } \\
\text { effectively }\end{array}$ & $\begin{array}{l}\text { Helpful and unhelpful thinking. } \\
\text { Identifications of cognitive distortions. Ruminative } \\
\text { style. Anti-rumination techniques. Problem solving and } \\
\text { distress tolerance. Mindfulness skills. }\end{array}$ \\
\hline 5 & Skilful behaviour & $\begin{array}{l}\text { Basic principles of behavioural change. Reinforcement } \\
\text { and extinction of behaviour. Opposite action. } \\
\text { Avoidance. The procrastination and antiprocrastination } \\
\text { cycle. Distress tolerance, anti-procrastination activities } \\
\text { and dismissing excuses. }\end{array}$ \\
\hline 6 & $\begin{array}{l}\text { The perfectionist } \\
\text { script for self-defeat } \\
\text { (Burns, } \\
\text { 1983) }\end{array}$ & $\begin{array}{l}\text { Self-esteem and perfectionism. Self-acceptance and } \\
\text { letting go. }\end{array}$ \\
\hline 7 & $\begin{array}{l}\text { The acceptance } \\
\text { paradox (Burns, } \\
\text { 1983) }\end{array}$ & $\begin{array}{l}\text { Paradox and contradiction. Acceptance and change. } \\
\text { Disputation of self-limiting beliefs. }\end{array}$ \\
\hline 8 & $\begin{array}{l}\text { Making } \\
\text { perfectionism work } \\
\text { for you }\end{array}$ & $\begin{array}{l}\text { Review of tools learned in the program. } \\
\text { Where to go from here? }\end{array}$ \\
\hline
\end{tabular}

\section{Thematic Analysis and Preliminary Discussion}

An analysis of the transcripts of the informal evaluation conducted at the end of the first pilot NIP revealed a number of themes. Those themes were: the positive effects of a group approach, the importance of focussing on cognitive distortions typical of PP and the potential benefits of the combination of mindfulness and traditional cognitive behavioural strategies.

\section{Positive Effects of a Group Approach}

Two of the participants' comments below illustrate some positive effects of the pilot program. John, a 35 year old project manager, diagnosed with chronic depression and anxiety found the program extremely helpful, with overall high satisfaction in the content and skills learned: 
"When I started the program I was a different person, someone nice to others, but not to myself, always giving myself a hard time, not respecting myself too much. I was angry, because I was critical of myself for not being good enough, all the time. The exercises we did in the last 8 weeks and this safe environment helped me have a better relationship with myself. Now I can achieve more. I feel more relaxed as I could get more of the group rather than sitting by myself, and talking to myself in that negative way".

Penny, a 42 year old accountant with generalised anxiety disorder and PP reported the group support and information as very relevant to understand her problems:

"Here in the group everyone is openly talking about their problems. I have never been in a group before. It is amazing, it is powerful. I can't even talk to my closest friends. Here is different, everybody is accepting, nobody is judging me or thinking: "She is strange" or "What is wrong with her?". Even my husband does that. He does not understand me. Here we all share our problems and it gives us confidence we are not alone, it gives us hope we can do something about things and we can improve. It's OK to have these problems because nobody is perfect..."I was trying to do all these things, all those rigid ideas, I thought it was good, I always tried to reach excellence in my life, I didn't want my life to be just "normal" but most of the time I suffer and I didn't understand why. Now I can relate these two things together. I made my life so hard, treating myself so strictly. I did not have fun in my life anymore".

As anticipated, the foundations of a group approach using principles of adult learning offered participants an non-threatening environment where problems could be analysed and effective problem solving, encouraged. The normalisation of emotions and the acknowledgement of the positive aspects of perfectionism allowed participants to take a more compassionate perspective on themselves. The collaborative alliance between facilitators and adult participants, the provision of information, skills and additional resources contributed to empower participants to take responsibility to address their problematic aspects of perfectionism. Notwithstanding the advantages of a group format, it must be noted that time constraints limit the individual attention that can be allocated to each participant. Some people with PP and comorbid anxiety or mood disorders may benefit from attending group skills training in parallel with individual therapy. The Dialectical Behavioural Therapy (DBT) model proposed such a complementary integration (Linehan 1993). 
Focus on Cognitive Aspects of PP

The importance of targeting cognitive aspects of perfectionism such as rigid, dichotomous thinking patterns and harsh self-criticism is illustrated by Lili's comments below.

Lili is a divorced 52 year old woman diagnosed with obsessive compulsive disorder and depression. She recently returned to university following a mental breakdown requiring inpatient care. She initially explained her rigid perfectionistic standards:

"at home, growing up, it was perfection or die. I could get $99 \%$ in a test and think: Why didn't I get 100\%? I tell myself: You're too lazy, you are not disciplined enough. That's why!"

Several comments from participants highlight the pain and suffering connected with unmet unrealistic expectations, punitive self-evaluation and dichotomous thinking.

"I feel devastated if I can't achieve what I set up to achieve and I tend to focus on what I have not achieved generally..." (John)

What follows is an illustration of a long term pattern of procrastination, connected with perfectionism, as well as the intense anguish and emotional pain suffered, written by one group participant (reproduced with permission)

"I am entirely filled with dread. Sick to the stomach. I cannot relax into anything else. Neither can I bite the bullet and deal with it. I am soft as a piece of yeast risen dough. Fragile and repulsively thin. I am scared. I feel incompetent. I want to escape. I want to vaporize. I have the feeling of slashing my wrists it is just high melodrama. It seems the only thing to bring relief. It is too hard. And I feel distressed. Only the sheer panic of failure, financial ruin, never to work again can see me through. I don't know the answer. I can't stand to go near it. I have no faith in my capacity. I fear the political ramification. I fear attack. I fear shame. I fear professional disgrace. I fear breakdown, meltdown, tears, I feel stuffing up. I fear reprisals, I fear hatred and loathing. I fear doing the wrong thing. I fear court proceedings. I can't bring myself to go there. I can't enjoy anything meantime. I can't spare the time to plan something. I feel guilty, burdened, trapped, I fear failing. I feel tired. I feel thin. I feel sad. I feel pained. I feel hyper-stressed. It takes a death moment, a rising up of such effort. And all the while the toxic pall of gas, toxic piles of paper emitting fumes, the kryptonite load which is awaiting attention which I fear and dread to approach..." (1)

Amy, a 49 year old participant, at the beginning of the group disclosed her chronic feelings and her lifelong pattern of perfectionism coupled with 
procrastination. Amy, a social policy writer and researcher who suffered from chronic depression and debilitating anxiety told us: "when I procrastinate (that is "all my life") I often think I am bad person". Additionally, a constant sense of pressure, self-rejection and inability to enjoy a sense of achievement is illustrated by another of her comments: "after the completion of my PhD. I just wanted to bury it six feet under".

Consistent with expectations, poor self-esteem and low self-efficacy were predominant features in all four participants who completed the first pilot NIP group. However, it is difficult to ascertain whether this was the result of other coexisting diagnoses, a lifelong pattern of self-derogation eroding self-esteem or their interaction. Nevertheless, intervention strategies to assist people with PP need to consider the fundamental role of cognitive factors in the PP remain crucial.

\section{Combination of Mindfulness and Cognitive Behavioural Strategies}

Clearly, more research is needed to confirm the validity and specific benefits of adding mindfulness to standard cognitive behaviour therapy (individual or group). In this paper, we provide anecdotal information about the potential benefits. Undoubtedly, there is yet limited empirical evidence of a relative increased efficacy of the addition of mindfulness into a cognitive behavioural treatment of perfectionism. As Egan et al. (2014) pointed out, there is no current data to substantiate claims that mindfulness and acceptance based approaches by themselves (standalone) are evidenced-based treatments for clinical perfectionism.

Lili's opinion below is suggestive of a positive reception of the NIP approach. Lili participated in previous therapeutic groups in a hospital environment but did not find them useful as she would not talk or disclose her difficulties in an effort to appear "perfect". When NIP was completed she told us:

"This group is really helpful for me. A major shift. I had the knowledge but no motivation to apply it, to put the information into action. I love the mindfulness meditation, it is beautiful. The first week I could not relate, did not have the space for it, but afterwards maybe as I was less angry, I received it better. I feel a lot of gratitude to people in this group. I always had a lot of trouble speaking in front of others, but here everyone is kind and warm, this is a place where I feel safe and I can share".

\section{Limitations}

There are several limitations that can be identified with the pilot program presented in this paper. First, the current paper is based on an initial trial of a first pilot program and on research in progress. Although tentative conclusions 
about the acceptance of the program can be drawn, further programs must be run before these conclusions can be accepted as definitive. Second, it is recognised that perfectionism is an enduring personality characteristic that may be resistant to change; the short duration of NIP is problematic, as some core constructs of perfectionism may require longer term and more intensive group and individual therapy rather than a short term group program, where some of the participants may not be willing to disclose their perceive imperfections due to a fear of rejection, feeling exposed and vulnerable. Furthermore, changing chronic patterns of behaviour requires information, skills and the internalisation of skills. Follow up is required to ascertain if participants continue to use the skills learned.

Third, the main assessment tools were clinical tools used for the anxiety and mood disorders, and therefore may not be sensitive to more subtle changes. Fourth, there were no strict exclusion criteria, and consequently, the participants presented with co-morbid disorders that may have complicated and decreased the effectiveness of the program.

Based on the qualitative feedback obtained from the initial NIP participants, some modifications will be introduced to the $2^{\text {nd }}$ and $3^{\text {rd }}$ pilot programs. These include:

1. Extension of the program duration to 12 sessions with a total of 24 hours of group therapy.

2. Extra sessions focussing on maladaptive thinking patterns and cognitive traps.

3. Follow up of participants at 3 months and 6 months.

4. Evaluation of the effectiveness of the program by the use of controls (clients of a university based counselling service and a convenience sample).

5. Introduction of new assessment tools and outcome measures.

Further studies, therefore, will benefit from a comparison of the perfectionistic self-schema and efficacy of psychological interventions combining mindfulness and cognitive behavioural therapy, in a clinical and a non-clinical population. Future research may need to investigate the specific contribution of mindfulness skills to help clients with PP above and beyond the use of a cognitive behavioural group approach. Additionally, more research is needed to ascertain which specific aspects of PP cognitive or behavioural treatment interventions must be prioritised.

\section{Conclusions}

This paper outlined an 8 week group program designed to address PP. The group's principles, structure and goals were introduced as well as the psychological strategies used to disrupt an unproductive cycle leading to low efficacy, poor self-esteem, and psychological distress. Even though only a pilot 
program was conducted, and current evidence of effectiveness is very limited, there is promising feedback from participants regarding the usefulness of the group and the supportive context in which the skills were learned. This initial pilot program enabled the identification of some limitations of the NIP program. It is hoped that these limitations will be further investigated and overcome in the second and third pilot programs.

\section{References}

Alidina S (2010) Mindfulness for dummies. West Sussex: John Wiley and Sons.

Antony M, Swinson R (2009) When perfect is not good enough: Strategies for Coping with clinical perfectionism. California: New Harbinger.

Arping-Cribbie CA, Irvine J, Ritvo P, Cribbie RA, Flett GL, Hewitt PL (2008) Perfectionism and psychological distress: A modeling approach to understanding their therapeutic relationship. Journal of Rational Emotional Cognitive Behaviour Therapy 26: 151-167. doi 10.1007/s10942-007-0065-2.

Baer RA (2003) Mindfulness training as a clinical intervention. A conceptual and clinical review. Clinical Psychology: Science and Practice 10: 125-143.

Ball J, Corry J, Mitchell P (2007) Mindfulness meditation and bipolar disorder. In DA Einstein (Ed) Innovations and Advances in Cognitive Behaviour Therapy. Queensland: Australian Academic Press.

Barlow DH (Ed.) (2008) Clinical handbook of psychological disorders, $4^{\text {th }}$ Edition. New York: Guilford Press.

Basco MR (2010) The procrastinator's guide to get things done. NY: Guilford Press.

Bassanini A, Caselli G, Fiore F, Ruggiero GM, Sassaroli S, Watkings ER, (2014) Why "why" seems better than "how". Processes underlining repetitive thinking in an Italian non-clinical sample. Personality and Individual Differences 64: 18-23. doi:10.1016/j.paid.2014.01.063.

Bein A (2013) Dialectical behaviour therapy for wellness and recovery: Interventions and activities. NY: John Wiley and Sons.

Blankstein KR, Lumley CH (2008) Multidimensional perfectionism and ruminative brooding in current dysphoria, anxiety and anger. Journal of Rational Emotional Cognitive Behaviour Therapy 26: 168-193. doi 10.1007/s10942-007-0068-z.

Brustein M (2014) Perfectionism: A guide for mental health professionals. New York: Springer.

Bullis JR, Sauer-Zavalla S, Bentley KH, Thompson-Hollands J, Carl JR, Barlow D (2015) The Unified protocol for transdiagnostic treatment of emotional disorders: Preliminary exploration of effectiveness for group delivery. Behaviour Modification 39(2): 295-321.

Burns D (1983) Ten days to self-esteem. New York: Quill William Morrow.

Carey TA (2011) Exposure and reorganization. The what and how of effective psychotherapy. Clinical Psychology Review 31: 236-248.doi:10.106/j.cpr.

Carmody J, Baer RA, Lykins ELB, Olendzki N (2009) An empirical study of the mechanisms of mindfulness in a mindfulness-based stress reduction program. Journal of Clinical Psychology 65: 1-14. doi: 10.102/jclp.20579.

Cayoun BA (2011) Mindfulness-integrated CBT: Principles and practice. Oxford: Wiley Backwell. 
Cayoun BA (2014) Why and how mindfulness meditation produces profound change: A new understanding of reinforcement mechanisms. Workshop presented APS College of Clinical Psychologists Conference. Melbourne, 20 June, 2014.

Cayoun BA (2015) Mindfulness-integrated CBT for well-being and personal growth: Four steps to enhance inner calm, self-confidence and relationships. Oxford: Wiley Backwell.

Dalton CC, Gotllieb LN (2003) The concept of readiness to change. Journal of Advanced Nursing 42(2): 108-117.

Dudley R, Kuykem W, Padesly CA (2011) Disorder specific and transdiagnostic case conceptualization. Clinical Psychology Review 31: 213-224. doi: 10.1016/j.crp. 2010.07.005.

Egan SJ, Wade TD, Shafran R (2011) Perfectionism as a transdiagnostic process: A clinical review. Clinical Psychology Review 31: 203-20.

Egan SJ, Wade TD, Shafran R, Anthony MM (2014) Cognitive behavioral treatment of perfectionism. New York. Guildford Press.

Flett GL, Hewitt PL (Eds) (2002) Perfectionism: Theory, research and treatment. Washington DC: American Psychological Association.

Flett GL, Hewitt PL, Davis RA, Sherry SB (2004) Description and counselling of the perfectionist procrastinator. In $\mathrm{H}$ Schowenburg (Ed) Counselling the procrastinator in an academic setting .Washington: APA.

Flett GL, Hewitt PL, Wheelan T, Martin TR (2007) The perfectionism cognitions inventory: Psychometric properties and associations with distress and deficits in cognitive self-management. Journal of Rational-Emotive \& CognitiveBehaviourTherapy 25(4): 255-277.doi: 10.1007/s10942-007-007-055-4.

Flett GL, Hewitt PL (2008) Treatment interventions for perfectionism -A cognitive perspective: Introduction to the special issue. Journal of Rational Emotional Cognitive Behaviour Therapy 26: 127-133. Doi 10.1007/s10942-007-0063-4.

Gallagher, MW, Bentley, KH, Barlow, DH (2014) Perceived control and vulnerability to anxiety disorders: A meta-analytic review. Cognitive Therapy Research, 38:571-584. doi: 10.1007/s10608-014-9624-х

Guindon MH (2010) Self-esteem across the lifespan: Issues and interventions. New York: Guilford.

Harvey A, Watkins E, Mansell W, Safran R (2009) Cognitive behavioural processes across psychological disorders: A trans-diagnostic approach to research and treatment. Oxford: Oxford University Press.

Hayes SC, Follette VM, Linehan MM (2011) Mindfulness and acceptance: Expanding the cognitive-behavioural tradition. NY: Guilford.

Higginson S, Mansell W, Wood A (2011) An integrative mechanistic account of psychological distress, therapeutic change and recovery: The Perceptual Control Theory approach. Clinical Psychology Review 31: 249-259. doi:10.1016/j.cpr. 2010.01.005.

Imel S (1998) Using principles of adult education in adult basic literacy education. Clearinghouse on Adult Career and Vocational Learning: Practice Application Brie, ERIC.

Kabat-Zinn J (1990) Full catastrophe living: Using the wisdom of your body and mind to face stress, pain and illness. New York: Delacorte.

Kabat-Zinn J, Massion AO, Hebert JR, Rosenbaum E (1998) Meditation. In JC Holland (Ed) Textbook on Psycho-oncology. Oxford, Oxford University Press.

Kabat-Zinn J (2003) Mindfulness based interventions in context: Past, present and future. Clinical Psychology: Science and Practice 10(2): 144-156. 
Kutlesa N, Arthur N (2008) Overcoming negative aspects of perfectionism through group treatment. Journal of Rational Emotional Cognitive Behaviour Therapy 26: 134-150. doi 10.1007/s10942-007-0064-3

Linehan MM (1993) Cognitive behavioral treatment of borderline personalitydisorder. New York: Guilford Press.

Linehan MM (2015) Dialectical behaviour therapy skills training manual: Handouts and worksheets, $2^{\text {nd }}$ Ed. Washington: Guilford Press.

McGonical K (2014) Open hearted acceptance meditation. Mindapps.

McNeill HP, Hughes CP, Toohey SM, Dowton B (2006) An innovative outcomebased medical education program built on adult learning principles. Medical Teacher, 28(6): 527-534. doi: 10.1080/0142159600834229.

Nhat Hanh T (1987) The miracle of mindfulness. Boston: Beacon Press.

Niemec RM (2014) Mindfulness and character strengths: A practical guide to flourishing. Boston: Hogrefe Publishing.

Nolen-Hoeksema S (1991) Responses to depression and their effects on the duration of depressive episodes. Journal of Abnormal Psychology 100: 569-582.

Nolen-Hoeksema S (2003) Women who think too much: How to break free of overthinking and reclaim your life. Kent: Piatkus.

Nolen-Hoeksema S, Wisco BE, Lyubomirsky S (2008) Rethinking rumination. Perspectives on Psychological Sciences, 3(5): 400-423.

Richard DCS, Lauterbach D, Gloster AT (2011) Description, mechanisms of action and assessment. In Richard, DCS, Leuterbach (Eds) Handbook of Exposure Therapies. Burlinghan: Academic Press

Robins CJ, Schmidt III H, Linehan MM (2004) Dialectical behaviour therapy: Synthesizing radical acceptance with skilful means. In SC Hayes, VM Follette, MM Linehan (Eds) Mindfulness and acceptance: Expanding the cognitivebehavioural tradition. NY: Guilford Press.

Rollnick S, Mason P, Butler C (1999) Health behaviour change: A guide for practitioners. London: Churchill Livingstone.

Santorelli SF, Kabat-Zinn J (Eds) (2009) Mindfulness-based stress reduction professional training resource manual: Integrating mindfulness meditation into Medicine and Health Care. MBSR Curriculum and Supporting Materials. University of Massachusetts Medical School.

Saulsman L, Nathan P (2008). Put off procrastination. Perth: Centre for Clinical Interventions.

Senderey E S (2014a) Nobody is Perfect: Addressing problematic perfectionism .Participant Workbook. Sydney: ACAP Psychology Clinic

Senderey ES (2014b) An innovative group therapy addressing perfectionism. Paper presented at the $9^{\text {th }}$ International Congress of Applied Psychology, Paris, $14^{\text {th }} \mathrm{July}$ 2014.

Scott MJ (2011) Simply effective: Group cognitive behaviour therapy-A practitioners's guide. New York: Routledge.

Shafran R, Cooper Z, Fairburn CG (2002) Clinical perfectionism: A cognitive behavioural analysis. Behaviour Research and Therapy 40: 773-791.

Shafran R, Egan SJ, Wade TD (2010) Overcoming perfectionism: A self-help guide using cognitive behavioural techniques. London: Robinson.

Shafran R, Mansell W (2001) Perfectionism and psychopathology: A review of research and treatment. Clinical Psychology Review 21(6): 879-906.

Short MM, Mazmanian D (2013) Perfectionism and negative repetitive thoughts: Examining a multiple mediator model in relation to mindfulness. Personality and Individual Differences 55: 716-721. 
Smith JM, Alloy LB (2009) A roadmap to rumination: A review of the definition, assessment, and conceptualization of this multifaceted construct. Clinical Psychology Review 29: 119-128. doi: 10.1016/j.cpr.2008.10.003.

Steele AL, Waite SJ, Finnigan J, Handley A, Wade TD (2012) Psychoeducation and group cognitive behavioural therapy for clinical perfectionism: A case series evaluation. Behavioural and cognitive psychotherapies 41: 129143. doi:10.1017/ S1352465812000628.

Teasdale JD, Segal Z, Williams JMG (1995) How does cognitive therapy prevents depressive relapse and why should attentional control (mindfulness) training help. Behaviour Research and Therapy 33(1): 25-39.

Wade T (2015) Treating clinical perfectionism. Workshop presented in APS College of Clinical Psychologists Conference. Adelaide, Australia, 26-28 June 2015.

Watkins ER (2009) Depressive rumination and co-morbidity: evidence for brooding as a transdiagnostic process. Journal of Rational Emotive Cognitive Behaviour Therapy 27: 160-175. 